\title{
Neurodevelopmental outcome and early rehabilitation of premature babies - is it needed in the first 2 years of life?
}

\author{
Jolanta Taczała ${ }^{1,2, A-F \oplus}$, Michał Latalski ${ }^{3, A-F} \oplus$, Magdalena Dmoszyńska-Graniczka ${ }^{2,4, A-F} \oplus$, \\ Anna Aftyka ${ }^{5, A-F} \oplus$, Piotr Majcher ${ }^{1, A-F \oplus}$ \\ ${ }^{1}$ Department of Rehabilitation and Physiotherapy, Medical University, Lublin, Poland \\ ${ }^{2}$ Department of Pediatric Rehabilitation, University Children's Hospital, Lublin, Poland \\ ${ }^{3}$ Children Orthopaedic Department, Medical University, Lublin, Poland \\ ${ }^{4}$ Department of Biochemistry and Molecular Biology, Medical University, Lublin, Poland \\ ${ }^{5}$ Department of Anaesthesiological and Intensive Care Nursing, Medical University, Lublin, Poland \\ A - Research concept and design, B - Collection and/or assembly of data, C - Data analysis and interpretation, \\ $D$ - Writing the article, E-Critical revision of the article, F- Final approval of article
}

Taczała J, Latalski M, Dmoszyńska-Graniczka M, Aftyka A, Majcher P. Neurodevelopmental outcome and early rehabilitation of premature babies - is it needed in the first 2 years of life? Ann Agric Environ Med. 2021; 28(1): 172-178. doi: 10.26444/aaem/122048

\begin{abstract}
Introduction and objective. The aim of the study was to evaluate the neurodevelopmental outcomes of extremely premature babies at the age of 2 years, and to determine whether rehabilitation was carried out during this period. An additional aim was to determine the relationship between the use of rehabilitation and the degree of prematurity, asphyxia, birth weight, and the result of brain ultrasound.

Materials and method. The study included 87 premature babies born between 24-31 weeks of pregnancy. A rehabilitation specialist assessed the neurodevelopmental outcomes of the children aged 2 years. Based on the documentation, the frequency of rehabilitation and its dependence on prematurity, asphyxia, birth weight and ultrasound results were analyzed. Results. Correct neurodevelopmental outcome in children aged 2 years was found in 57 (65\%) children, of whom 40 (46\%) did not undergo rehabilitation. Incorrect development was observed in a group of 30 children - 12 patients were diagnosed with CP (14\%), and 18 (21\%) had 'red flags' of development milestones, they underwent rehabilitation. There was no statistically significant relationship between the degree of prematurity, perinatal asphyxia, birth weight and rehabilitation in the first 2 years of life. Abnormal ultrasound results were more common in rehabilitated children $(n=25 ; 53 \%)$ than in children without rehabilitation $(n=10 ; 25 \%), p=0.008$.

Conclusions. Correct neurodevelopmental outcome at the age of 2 reached two-thirds of extreme prematurities, most of which did not need rehabilitation during this period. According to the authors' knowledge, this is the first study to show the percentage of premature babies who in the first 2 years of life did not require rehabilitation and achieved normal development.
\end{abstract}

\section{Key words}

prematurity, rehabilitation, psychomotor development, milestones, socio-economic dimension

\section{INTRODUCTION}

Extreme prematurity, low birth weight and asphyxia are major risk factors that can cause early brain damage in children $[1,2,3,4]$. The shorter the duration of pregnancy, the lower the birth weight, the smaller the number of points on the Apgar scale, the higher the risk of developmental disorders $[5,6,7]$. This group of 'risk children' requires the monitoring of psychomotor development. If there is a delay or abnormal development, it is advisable to conduct early rehabilitation. Diagnosis of disorders is difficult because preterm delivery changes developmental trajectories, which is why premature babies may reach developmental stages at a different time and order $[8,9]$. In premature babies, the corrected age should be taken into account [10].

Early rehabilitation in premature babies is important due to greater brain plasticity in the first months of life and the lack of fixed pathological movement patterns $[11,12,13]$. On the

Address for correspondence: Jolanta Taczała, Department of Rehabilitation and Physiotherapy, Medical University of Lublin, Poland

E-mail: jolantataczala@umlub.pl

Received: 02.04.2020; accepted: 05.05.2020; first published: 14.05.2020 other hand, it should be remembered that any intervention should be justified, as it is not a matter of indifference to the child and the family $[14,15,16]$. Not all premature babies or a child born in severe asphyxia require early rehabilitation. There is a group of children who, despite significant loads during the pregnancy and perinatal period, do not have clinical signs of abnormal development $[17,18]$. All infants at risk should be monitored for development, but rehabilitation should only be used when there are obvious indications [12]. There are papers in the literature describing the negative effects of unnecessary rehabilitation $[19,20]$. The above knowledge obliges us to apply strictly defined qualification criteria for early rehabilitation in children at risk, including premature babies. Hence the need for a study like this one, the objectives of which are described below.

\section{OBJECTIVE}

The aim of the study was to determine the neurodevelopmental outcome of extreme premature babies aged 2 years in the context of conducted or not conducted rehabilitation. An 
additional aim was to determine whether rehabilitation depended on the degree of prematurity, birth weight, the Apgar score at the first minute after birth, and the result of brain ultrasound (cranial ultrasonography - cUS).

\section{MATERIALS AN METHOD}

Out of 465 children referred to the day-care unit, 125 premature babies (born before 32 weeks of gestation) were selected for the study. They were born between September 2015 - August 2017. The study excluded 38 children with incomplete medical records. They were children who were did not have follow-up visits or remained under observation for less than 2 years. In the final study group, 87 children (40 boys and 47 girls) were selected who had parental consent and full medical records of their psychomotor development from 2-24 months of age. Information cards from the newborn period were used to assess risk factors from the gestational and perinatal period, while documentation for the rehabilitation centre was used to analyze the frequency of applied rehabilitation. For the purposes of this study, the following data was obtained from information cards: gestational age, the Apgar score at 1 minute after birth, birth weight, and the result of brain ultrasound performed at a time close to delivery.

Due to the degree of prematurity, group A - for children born before the 28th week of pregnancy, and group B - for children born between 28 - 31 weeks were separated. Based on the Apgar score at 1 minute, researchers distinguished children born: in severe asphyxia when the score ranged from 0 - 3; in moderate asphyxia when the score ranged from 4 7 ; without asphyxia when the score ranged from $8-10$. The criterion of birth weight (BW) allowed researchers to divide the children into groups: BW under $1,000 \mathrm{~g}$; BW between 1,001 - 1,500g; BW between 1,501 - 2,500g. Description of the cUS at the time close to delivery was interpreted as normal or abnormal; the degree of pathology described was not differentiated.

Development assessment was carried out by a physician - a specialist in medical rehabilitation at $1,2,4,6,9,12,18$ and 24 months of age. For premature babies in the first year of life, the corrected age was taken into account. Study cards for the above age groups were organized. They contained an assessment of the position/posture and movement pattern, symmetry, and muscle tone. For children aged 2 and 4 months, General Movement Assessment (GMA) according to Prechtl was used. From 6 months, spasticity assessment was also evaluated according to the Tardieu scale, as well as the presence of selective movements of upper and lower limbs in spontaneous movements. The physician assessed milestones of psychomotor development in the areas of: gross and fine motor skills, communication, cognitive and socio-emotional development, paying special attention to alarm symptoms, the so-called 'red flags' (RFs) of development milestones at months, listed above. They were developed by CF Dosman based on scientific research [21]. The eligibility criteria for rehabilitation are described below. Infants who were found to have abnormal posture/movement and movement patterns, abnormal Prechtl GMA, postural asymmetry, muscle tone disorders, including spasticity, and lack of movement selectivity, were referred to a physiotherapist. Feeding or communication disorders were the reason for referral to a speech therapist, and irregularities in the development of cognitive and socio-emotional functions - to a psychologist. Monitoring the development of children from the very beginning was based on close cooperation with parents - the physician discussed with parents the next stages of development with the use of alarm symptoms.

The main studies were conducted from September 2017 September 2019. Children aged 2 years were examined by a physician, and then classified into 3 groups: I - healthy, II with cerebral palsy (CP), and III - with doubtful development, requiring further observation. For a better understanding of the final examination methodology and qualification of children to a group requiring observation, a study card used for 2-yearold children is presented (Fig. 1). The correct posture and movement pattern, neurological status and lack of RFs in the milestones of psychomotor development were found in group I children. Group II children had clinical symptoms of CP confirmed by neurological examination. Small developmental deficits and RFs of development milestones were present in group III children. Based on the medical documentation collected in the 2-year period, a retrospective analysis of the conducted rehabilitation was carried out.

Analysis was conducted in statistical package $\mathrm{R}$ (version 3.6.1). Data was presented as $n$ (\% of group). Variables were analyzed among the groups with chi-square test or Fisher exact test, as appropriate. All tests were 2 -tailed and results were regarded as statistically significant at $p<0.05$.

\section{RESULTS}

Group characteristics: Out of a total of 87 premature babies examined, $29 \%(n=25)$ were born between $22-27$ weeks (group A), and the remainder $71 \%(n=62)$ were born between 28 - 31 weeks (group B). Asphyxia occurred in 80 infants (92\%): moderate asphyxia in 67 children and severe asphyxia in 13 children. There was a statistical difference in the incidence of asphyxia in groups $A$ and $B, p<0.001$. Lack of asphyxia was found only in children in group $B$, moderate asphyxia was more common in group B than group A $(84 \%$ vs. $60 \%$ ), while severe asphyxia was mainly found in group A ( $40 \%$ vs. $5 \%$ in group B). Group B children also had a much more frequent normal cUS result than group A, $68 \%$ vs. $40 \%$, $\mathrm{p}=0.017$ (Table 1$)$.

Table 1. Characteristic of study groups

\begin{tabular}{|c|c|c|c|c|c|}
\hline Characteristic & Value & $\begin{array}{c}\text { Total } \\
\text { group }\end{array}$ & $\begin{array}{c}\text { Group A } \\
(22-27 \\
\text { hbd })\end{array}$ & $\begin{array}{c}\text { Group B } \\
(28-31 \\
\text { hbd })\end{array}$ & $P$ \\
\hline$n$ & & 87 & 25 & 62 & \\
\hline \multirow{3}{*}{ Asphyxia } & No (Apgar 8-10) & $7(8.0)$ & - & $7(11.3)$ & \multirow{3}{*}{$<.001^{*}$} \\
\hline & Moderate (Apgar 4-7) & $67(77.0)$ & $15(60.0)$ & $52(83.9)$ & \\
\hline & Severe (Apgar 0-3) & $13(14.9)$ & $10(40.0)$ & $3(4.8)$ & \\
\hline \multirow{4}{*}{ Birth weight } & Above $2,500 \mathrm{~g}$ & - & - & - & \multirow{4}{*}{$-<.001^{*}$} \\
\hline & $1,500-2,499 \mathrm{~g}$ & $19(21.8)$ & - & $19(30.6)$ & \\
\hline & $1,000-1,499 \mathrm{~g}$ & $42(48.3)$ & $8(32.0)$ & $34(54.8)$ & \\
\hline & Below $1,000 \mathrm{~g}$ & $26(29.9)$ & $17(68.0)$ & $9(14.5)$ & \\
\hline \multirow{2}{*}{ cUS } & Correct & $52(59.8)$ & $10(40.0)$ & $42(67.7)$ & \multirow{2}{*}{.017} \\
\hline & Not correct & $35(40.2)$ & $15(60.0)$ & $20(32.3)$ & \\
\hline
\end{tabular}

${ }^{1}$ Data are presented as $n$ (\% of group). Groups A and B are compared by chi-square test or Fisher exact test $\left({ }^{*}\right.$. 


\section{Examination card for 2-year-old children (24 months)}

\section{Part I}

First name and last name................................ Age ........ Weight -

Posture: symmetry/asymmetry of the spine in sitting/standing position: yes/no (describe)

Gait pattern: normal/abnormal (describe)

Hips: correct - no (describe)

Selective movements: hands - yes/no; feet yes/no

Spasticity (Tardieu Scale):

Upper extremity: no/yes: arm (left/right); forearm (left/right); wrist (left/right)

Lower extremity: no/yes: hip adductors (left/right); knees (left/right); feet (left/right)

\section{Part II}

'Red flags' of developmental milestones (developed by CF Dosman et al. [21])

\begin{tabular}{||l|l|l|}
\hline $\begin{array}{l}\text { Sectors of } \\
\text { development }\end{array}$ & child skills & Yes/No \\
\hline Gross Motor & $\begin{array}{l}\text { Runs, jumps, kicks } \\
\text { Throws ball overhand three feet forward } \\
\text { Walks upstairs marking time, no railing }\end{array}$ & \\
\hline Fine motor & $\begin{array}{l}\text { Copies vertical line } \\
\text { Stacks six cubes } \\
\text { Uses spoon, helps dress }\end{array}$ & \\
\hline Speech-language & $\begin{array}{l}\text { 50 words, two-word phrases } \\
\text { Talks instead of gestures } \\
\text { Nods 'yes', blows kisses,'sh', 'high five' (representation) } \\
\text { Speech 50\% intelligible to strangers }\end{array}$ & \\
\hline Cognitive & $\begin{array}{l}\text { Symbolic representation, simple pretend (toy broom, toy } \\
\text { cup to self/doll, pushes toy car to work } \\
\text { Strategies without rehearsal } \\
\text { Tries to make toys work }\end{array}$ & \\
\hline Social-emotional & $\begin{array}{l}\text { Social referencing } \\
\text { Comforts others (empathy) } \\
\text { Joint attention: points to clarify word approximations } \\
\text { Parallel play } \\
\text { 'No', 'Mine' }\end{array}$ & \\
\hline
\end{tabular}

Figure 1. Examination card for 2-year-old children 
Results of the final examination of 2 -year-old children. Out of the whole group of 87children, 57 (65.5\%) aged 2 years developed properly, with no significant difference between groups A and B (64.0 vs. 66.1\%). RFs of psychomotor development at the age of 2 were observed in 18 children (20.7\%). The differences between group A and B were also not statistically significant, but more children with doubtful development were in group B (16\% vs. 22.6\%). CP was diagnosed in 12 children (13.8\%), but in Group A they constituted a higher percentage than in Group B $(20.0 \%$ vs. $11.3 \%)$. Functional assessment on the GMFCS scale was performed in children with CP. The results are presented in Table 2.

Table 2. Children with diagnosed $\mathrm{CP}^{1}$

\begin{tabular}{lcccccc}
\hline GMFCS & 1 & 2 & 3 & 4 & 5 & Combined \\
\hline $\mathrm{n}$ & 7 & 1 & 2 & 2 & 0 & 12 \\
\hline$\%$ & 58,33 & 8,33 & 16,67 & 16,67 & 0 & 100
\end{tabular}

${ }^{1}$ Number $(\mathrm{n})$ and $\%$ for each GMFCS level

Neurodevelopmental outcome at 2 years of age and frequency of rehabilitation. Rehabilitation in the first 2 years of life was used in $54 \%$ of the whole group ( $n=47)$. In this group, 17 children (20\% of the whole group) achieved normal development at the age of 2; CP was diagnosed in $12(14 \%)$ children, and the remaining 18 (21\%) children required further developmental observation. There was no statistical difference in the frequency of rehabilitation used between groups A and B, 64\% in group A vs. 50\% in group B. Among the entire study group, 40 children (46\%) did not have any rehabilitation and their development at the age of 2 was normal. Table 3 shows the results of the final evaluation of children and the frequency of rehabilitation used.

Table 3. Neurodevelopmental outcome at 2 years of age and frequency of rehabilitation in premature babies ${ }^{1}$

\begin{tabular}{|c|c|c|c|c|c|}
\hline Characteristic & Value & $\begin{array}{l}\text { Total } \\
\text { group }\end{array}$ & $\begin{array}{c}\text { Group A } \\
(22-27 \mathrm{hbd})\end{array}$ & $\begin{array}{c}\text { Group B } \\
(28-31 \mathrm{hbd})\end{array}$ & $\mathrm{p}$ \\
\hline$n$ & & 87 & 25 & 62 & \\
\hline \multirow{2}{*}{$\begin{array}{l}\text { Rehabilitation in } 24 \\
\text { months }\end{array}$} & Yes & $47(54.0)$ & $16(64.0)$ & $31(50.0)$ & \multirow{2}{*}{.236} \\
\hline & No & $40(46.0)$ & $9(36.0)$ & $31(50.0)$ & \\
\hline \multirow{3}{*}{$\begin{array}{l}\text { Assessment of } \\
\text { development at } 24 \\
\text { months }\end{array}$} & Correct & $57(65.5)$ & $16(64.0)$ & $41(66.1)$ & \multirow{3}{*}{$.532^{*}$} \\
\hline & $\begin{array}{l}\text { Cerebral } \\
\text { palsy }\end{array}$ & $12(13.8)$ & $5(20.0)$ & $7(11.3)$ & \\
\hline & $\begin{array}{l}\text { Observation } \\
\text { needed }\end{array}$ & $18(20.7)$ & $4(16.0)$ & $14(22.6)$ & \\
\hline
\end{tabular}

' Data are presented as $n$ (\% of group). Groups A and B are compared by chi-square test or Fisher exact test $(*)$.

Prematurity, asphyxia, birth weight and ultrasound, and frequency of rehabilitation. As described above, of 47 (54\%) rehabilitated children, asphyxia occurred in 43 (92\%): moderate in 33 children and severe in 10 children (Tab. 4). No statistically significant relationship was found between asphyxia or low birth weight and the use of rehabilitation in the first 2 years of life. In contrast, abnormal ultrasound results occurred in the group of rehabilitated children in 25 (53\%), and were much more frequent compared to children without rehabilitation $(25 \%)(\mathrm{p}=0.008)$.
Table 4. Comparison of children with and without rehabilitation in first 2 years $^{1}$

\begin{tabular}{lcccc}
\hline Characteristic & Value & $\begin{array}{c}\text { Total } \\
\text { group }\end{array}$ & $\begin{array}{c}\text { No } \\
\text { rehabilitation } \\
\text { in 2 years }\end{array}$ & $\begin{array}{c}\text { Rehabilitation } \\
\text { in 2 years }\end{array}$
\end{tabular}$\quad$ p

1 Data are presented as $n$ (\% of group). Groups are compared by chi-square test or Fisher exact test $(*)$.

\section{DISCUSSION}

The clinical and scientific studies to-date regarding diagnostic and therapeutic methods in use and early intervention programmes for premature babies show that there are no clear guidelines $[1,2,11,12,22,23,24]$. It is difficult to find articles on premature babies that do not require any form of therapy. There are definitely more descriptions of methods for early diagnosis and rehabilitation of premature babies who are exposed to early brain damage and its consequences $[25,26,27,28,29]$. Cerebral palsy and autism are examples of the most serious diseases occurring in the group of neurodevelopmental disorders (NDI) in premature babies $[30,31,32,33]$. Depending on the degree of prematurity, the risk of developing $\mathrm{CP}$ increases. In the meta-analysis developed by Himpens E. at al., it was observed that among children born $<28$ weeks, the frequency of CP was $14.6 \%$, and among those born at 28-31 weeks $-6.8 \%$ [5]. In our studies, the percentage of CP-children was definitely higher than presented in the above-mentioned meta-analysis; for premature babies $<28$ weeks $20 \%$, and for premature babies 28-31 weeks - $11.3 \%$.

Due to the high risk of neurodevelopmental disorders in premature infants, NDI-free survival at 2 years has become a common reference point for success. NDI is defined as one or more of the following after 2 years: moderate to severe cerebral palsy, profound hearing loss, profound visual impairment, moderate to deep cognitive lag (Bayley-III) and/or motor disorders III - V level GMFCS [18, 34]. Rysavy et al. describe that in recent years the percentage of extreme premature babies whose development is normal at the age of 2 is increasing. The percentage of extreme premature babies (< 28 weeks) who do not have NDI at 2 years increased from 16 to $20 \%$ in 2000-2011 [34]. The research presented by the authors included a group of children born $<32$ weeks, in which the lack of NDI at the age of 2 years was $65.5 \%$. In a separate group of premature babies born $<28$ weeks of gestation, the percentage of children without NDI was high and amounted to $64 \%$. This is over 3 times more than in Rysava's research. Such a significant difference led the authors to think about 
the results obtained. The group of children studied was similar, and the medical examination supplemented with assessment of the development milestones in 5 sectors: gross motor, fine motor, communication, cognitive and socialemotional functions, taking into account the so-called 'red flags'. Serious neurological disorders, such as cerebral palsy, were excluded or confirmed by neurological examination. Bayley III was not used to assess cognitive impairment. Vision, hearing and cognitive deficits were included in the milestone alarm symptoms. In our study, $21 \%$ of children required follow-up development due to the RFs of milestones at the age of 2 years. Despite another research tool being used, the results obtained by the authors are satisfactory. The answer to the question whether such a big difference results from another research tool, which seems unlikely, or whether it results from more effective therapy compared to studies from 9 years ago, remains open. According to the authors, close cooperation with parents and discussion of abnormal development signs, especially in the first 6 months of life (medical examination at 1, 2, 4 and 6 months of age) may have a significant impact on a good final result with reduced rehabilitation frequency.

As described in the Introduction, rehabilitation is not indifferent to the child and the family; therefore, one of the aims of the study was to determine the percentage of children not rehabilitated for the first 2 years. Almost half of the examined children (46\%) did not require rehabilitation and achieved normal psychomotor development. One third of children (34.5\%) needed rehabilitation due to CP diagnosis (13.8\%) or symptoms of abnormal psychomotor development (20.7\%), the so-called 'red flags'. They mainly involved the areas of communication development, and cognitive and socio-emotional functions. Movement retardation resulted from coexisting joint flaccidity, which is an individual trait and usually does not require treatment [17]. The remaining 17 children had rehabilitation, but achieved normal development at the age of 2 years.

For parents/caregivers, the first year of life of a premature baby is a special period of their sensitivity to any information about a threat to the child's health. Qualification for rehabilitation in this early period should be closely examined in order to it to be justified $[35,36]$. Another important advantage of using RFs was the possibility of joint observation of child development and discussing current development deficits. Thanks to this, parents can conduct rehabilitation themselves in a family environment, i.e. the most optimal for a child [11]. Doing so may reduce a child's stress level, build a sense of security, and increase the activity of the 'little patient' in learning about the surrounding environment. This is in line with current recommendations, the aim of which is to optimize participation. Programmes that stimulate all aspects of infant development through family 'coaching' are the most promising $[15,37]$.

In the group of premature babies, apart from prematurity, other developmental risk factors often co-exist: asphyxia, low body weight, and brain damage confirmed by imaging tests $[38,39,40]$. The results of the presented studies indicated that the dependence of the frequency of rehabilitation used on the degree of prematurity, asphyxia and low birth weigh, were not statistically significant. In contrast, an abnormal brain ultrasound result was correlated with more frequent use of rehabilitation $(\mathrm{p}=0.008)$. Research results indicate that the mere fact of the occurrence of risk factors is not synonymous with the need for the early rehabilitation of infants. In contrast, damage to the central nervous system, confirmed by imaging, requires more early intervention [41].

Parents of prematurely born children have referrals to many specialist clinics once their infants are discharged. On the one hand, they must provide the child with medical check-ups; on the other hand, the child needs a peaceful and safe home environment. The experiences associated with hospitalization in the ICU, and the impact of pain and stress in this first period have a proven adverse effect on later development $[42,43,44]$. During the examination, an inadequate reaction of the child to the examiner can often be observed as a consequence of past stress. This is an important reason that a referral for rehabilitation to another 'foreign' person should be justified. The model of monitoring infant development used by the authors (described in the Methodology) allows almost half of the children from the group at high risk of developmental disorders, not to target rehabilitation or additional developmental assessments, achieving normal development without NDI.

The results emphasize the importance of monitoring the early psychomotor development of extreme premature babies by a rehabilitation doctor. Professional experience in working with older disabled children and their families allows us to see the need to protect premature babies and their parents from unnecessary therapeutic intervention in the first months of life. It is known that early intervention is necessary due to the greatest brain plasticity in the first half year of life, the 'critical windows' for the development of individual senses in this period $[45,46]$. However, it should be remembered that unnecessary rehabilitation is not a matter of indifference to the infants and their families. There is growing scientific evidence for the negative effects of unnecessary intervention for both children and parents who have already undergone high levels of stress [19, 20, 47, $48,49]$. An ordered system of monitoring the development of children at risk in a specialist centre for the first 2 years allows the earliest detection of developmental disorders and the implementation of appropriate therapy. Above all, however, it protects children from unnecessary intervention and strengthens the competences of parents and guardians. Most of the neurodevelopmental deficits in premature babies are mild to moderate, not covered by the NDI criteria [32]. On the other hand, cognitive and socio-emotional disorders may appear in old age in the absence of NDI in infancy [50, $51,52]$. Therefore, further long-term development follow-up after 2 years is necessary [53].

The authors also emphasize the socio-economic aspect of the research. Extreme premature babies are at risk of disability and need monitoring of their development, but do not always require rehabilitation. This problem also requires further research. On the one hand there are more and more therapists dealing with early rehabilitation; on the other hand, there are scientific evidences describing the harmful effect of unnecessary interventions on children's development, on the level of stress in parents, and the deterioration of family functioning. The unnecessary costs of intervention must also be emphasized.

Our research results are difficult to compare with those by other authors due to the RFs used to evaluate development milestones, described by Dosman et al. [21]. Using RFs, in the authors' opinion, can be valuable tools in observing psychomotor development of children as well as qualification 
for early physiotherapists, speech therapists, and psychologists intervention. This research is part of a project aiming to find the best model for monitoring the psychomotor development of infants at risk. In further work, we plan to supplement the methodology with research tools that enable comparison of results with other studies.

\section{CONCLUSIONS}

- The presence of prematurity does not determine the need for infant rehabilitation.

- Monitoring of the development of premature babies by a physician allows qualification for therapy according to strictly defined indications to avoid unnecessary intervention.

- Asphyxia or low birth weight are indications for monitoring of psychomotor development but not always for rehabilitation.

The study was conducted with the consent of the Bioethical Commission No. KE-0254/222/2017 of the Medical University of Lublin and is the first part of the research - a retrospective analysis of the psychomotor development of children at risk.

\section{REFERENCES}

1. Novak I, Morgan C, Adde L, et al. Early, Accurate Diagnosis and Early Intervention in Cerebral Palsy Advances in Diagnosis and Treatment. JAMA Pediatr. 2017; 171(9): 897-907.

2. Spittle AJ, Morgan C, Olsen JE, Novak I, Cheong JL. Early Diagnosis and Treatement of Cerebral Palsy in Children with a History of Preterm Birth. Clin Perinatol. 2018; 45(3): 409-420.

3. Herskind A, Greisen G, Nielsen JB. Early identification and intervention in cerebral palsy. Dev Med Child Neurol. 2015 Jan; 57(1): 29-36.

4. Bosanquet M, Copeland L, Ware R, Boyd R. A systematic review of tests to predict cerebral palsy in young children. Dev Med Child Neurol. 2013; 55: 418-26.

5. Himpens E, Van den Broeck C, Calders P, Vanhaesebruck P. Prevalence, type, distribution and severity of cerebral palsy in relations to gestational age: a metaanalytic review. Dev Med Child Neurol. 2008 May; 50(5): 334-40.

6. Platt MJ, Cans C, Johnson A, et al. Trends in cerebral palsy among infants of very low birthweight $(<1500 \mathrm{~g})$ or born prematurely ( $<32$ weeks) in 16 European centres: a database study. Lancet 2007; 369: 43-50.

7. Pelc K, Daniel I, Wenderickx B, Dan B. Primebrain group. Multicentre prospective randomised single-blind controlled study protocol of the effect of an additional parent-administered sensorimotor stimulation on neurological development of preterm infants: Primebrain. BMJ Open. 2017 Dec 3; 7(12).

8. Tamis W. Pin a, Bev Eldridge b, Mary P. Galea: Motor trajectories from 4 to 18 months corrected age in infants born at less than 30 weeks of gestation. Early Hum Dev. 2010; 86: 573-580.

9. Maitre NL, Slaughter JC, Aschner JL. Early prediction of cerebral palsy after neonatal intensive care using motor development trajectories in infancy. Early Hum Dev. 2013; 89: 781-6.

10. Kułakowska Z. Some aspects of early diagnosis of brain lesions in newborn. Ped Pol. 2007; 82(10): 816-823.

11. Hadders-Algra M. Early Diagnosis and Early Interwention i Cerebral Palsy. Frontiers in Neurology 2014.

12. Cioni Giovanni, Inguaggiato Emanuela, Sgandurra Giuseppina. Early intervention in neurodevelopmental disorders: underlying neural mechanisms. Dev Med Child Neur. 2016; 58(Suppl. 4): 61-66.

13. Hadders-Algra M. Early brain damage and the development of motor behavior in children: clues for therapeutic intervention? Neural Plast. 2001; 8: 31-49.

14. Spittle A, Trevvaud K. The role of early developmental intervention to influence neurobehavioral outcomes of children born preterm, Semin Perinatol. 2016 Dec; 40(8): 542-548.
15. White-Traut RC1, Rankin KM2, Yoder J3, Zawacki L4, Campbell S5, Kavanaugh K6, Brandon D7, Norr KF3. Relationship between motherinfant mutual dyadic responsiveness and premature infantdevelopment as measured by the Bayley III at 6 weeks corrected age. Early Hum Dev. 2018 Jun; 121: 21-26.

16. Howe TH, Sheu CF, Wang TN, Hsu YW. Parenting stress in families with very low birth weight preterm infants in early infancy. Res Dev Disabil. 2014 Jul; 35(7): 1748-56.

17. Hashkes PJ. Joint laxity is not equal to hypermobility in preterm born in children. J Ped. 2018; 197: 104-5.

18. Duncan AF, Matthews MA. Neurodevelopmental Outcomes in Early Childhood. Clin Perinatol. 2018; 45: 377-392.

19. Guzzetta A, Baldini S, Bancale A, et al. Massage accelerates brain development and the maturation of visual function. J Neurosci. 2009; 29: $6042-5$.

20. Linsell L, Malouf R, Marlow N, et al. Prognostic Factors for Poor Cognitive Development in Children Born Very Preterm or With Very Low Birth Weight: A Systematic Review. Jama Pediatrics 2015; 169(12): 1162-1172.

21. Dosman CF, Andrews D, Goulden K. Evidence-based milestone ages as a framework for developmental surveillance. Paediatr Child Health 2012; 17: 561-568.

22. Novak I, Hines M, Goldsmith S, et al. Clical prognostic messages from a systematic review on cerebral palsy. Pediatrics 2012; 130(5): 1285-312.

23. Novak I, Mcintyre S, Morgan C, et al. A systematic review of interventions for children with cerebral palsy: state with the evidence. Dev Med Child Neurol. 2013; 55: 885-910.

24. Schandel D, Bhasin TK. Birth weight and gestational age characteristics of children with autism including a comparison with other developmental disabilities. Pediatrics 2008; 121: 1155-1164.

25. Morgan C, Darrah J, Gordon AM, Harbourne R, Spittle A, Johnson R, Fetters L. Effectiveness of motor interventions in infants with cerebral palsy: a systematic review. Dev Med Chil Neur. 2016; 58: 900-909.

26. Ferrari A. Cioni G. The Spastic Form of Cerebral Palsy. A Guide to the Assessement of Adaptive Functions. 2010, Springer-Verlag Italia, $31-50$.

27. Kilincaslan A, Mukaddes NM. Pervasive developmental disorders in individuals with cerebral palsy. Dev Med Child Neurol 2009; 51: 289-94.

28. Einspieler C, Prechtl HF. Prechtl's assessment of general movements: a diagnostic tool for the functional assessment of the young nervous system. Ment Retard Dev Disabil Res Rev. 2005; 11(1): 61-67.

29. Einspieler C, Marschik PB, Bos AF, Ferrari F, Cioni G, Prechtl HF. Early markers for cerebral palsy: insights from the assessment of general movements. Future Neurol. 2012; 7: 709-717.

30. Pierce K, Carter C, Weinfield M, et al. Detecting, studying, and treaning autism early: The one-year well-baby check-up approach. J Pediatr. 2011; 159: 458-465.

31. Rutkowska M, Bekiesińska-Figatowska M, Kmita G, Terczyńska I, Polak K, Kalisiak M, Prażmowska D, Kiepura E, SzkudlińskaPawlak S, Seroczyńska M, Helwich E. Neuroimaging results, shortterm assessement of psychomotor development and the risk of autism spectrum disorder in extremly premature infants $<28 \mathrm{GA}$ ) a prospective cohort study (preliminary report). Developmental Period Medicine 2018; XXII(1): 39-48.

32. Younge N, Goldstein RF, Bann CM, et al. Eunice Kennedy Shriver National Institute of Child Health and Human Development Neonatal Research Network. Survival and neurodevelopmental outcomes among periviable infants. N Engl J Med. 2017; 376(7): 617-28.

33. Moore T, Hennessy E, Myles J, et al. Neurological and developmental outcome in extremely preterm children born in England in 1995 and 2006: the EPICure studies. BMJ 2012; 345: 1-15.

34. Rysavy MA, Li L, Bell EF, et al. Eunice Kennedy Shriver National Institute of Child Health and Human Development Neonatal Research Network. Between-hospital variation in treatment and outcomes in extremely preterm infants. N Engl J Med. 2015; 372(19): 1801-11.

35. Howe TH, Sheu CF, Wang TN, Hsu YW. Parenting stress in families with very low birth weight preterm infants in early infancy. Res Dev Disabil. 2014 Jul; 35(7): 1748-56.

36. White-Traut RC, Rankin KM, Yoder J, Zawacki L, Campbell S, Kavanaugh K, Brandon D, Norr KF. Relationship between motherinfant mutual dyadic responsiveness and premature infantdevelopment as measured by the Bayley III at 6 weeks corrected age. Early Hum Dev. 2018 Jun; 121: 21-26.

37. Palisano RJ, Chiarello LA, King GA, Novak I, Stoner T, Fiss A. Participation-based therapy for children with physical disabilities. Disabil Rehabil. 2012; 34: 1041-52. 
38. Chattopadthyay N, Mitra K. Neurodevelopmental outcome of high risk newborns discharged from special care baby units in a rural districts in India. J Public Health Res. 2015; 4: 318.

39. Colver A, Fairhurst C, Pharoah P. Cerebral palsy. Lancet 2014; 383: 1240-49.

40. Diwakar RK, Khurana O. Cranial Sonography in Preterm Infants with Short Review of Literature. J Pediatric Neurosci. 2018; 13(2): 141-149.

41. Reid SM, Dagia CD, Ditchfield MR, Carlin JB, Reddihough DS. Population-based studies of brain imaging patterns in cerebral palsy. Dev Med Child Neurol. 2014; 56: 222-32.

42. Muller-NC, Forcada-Guex M, Pierrehumbert B, et al. Prematurity, maternal stress and mother-child interactions. Early Hum Dev. 2004; 2: $145-158$.

43. Spittle A, Treyvaud K. The role of early developmental intervention to influence neurobehavioral outcomes of children born preterm. Semin Perinatol. 2016; 40(8): 542-8.

44. Cong X, Wu J, Vittner D, Xu W, Hussain N, Galvin S, Fitzsimons M. The Impact of Cumulative Pain/Stress on Neurobehavioral Development of Preterm Infants in the NICU. Early Hum Dev. 2017 May; 108: 9-16.

45. Als H, Duffy FH, McAnulty GB, Rivkin MJ, Vajapeyam S, Mulkern RV, Warfield SK, Huppi PS, Butler SC, Conneman N, et al. Early experience alters brain function and structure. Pediatrics, 2004 Apr; 113.
46. Graven S, Browne JV. Sensory Development in the Fetus, Neonate, and Infant: Introduction and Overview. Newborn Infant Nurs Rev. 2008; 8(4): 169-172.

47. Novak I, Thornton N, Morgan M, et al. Truth with hope: ethical challenges in disclosing „bad” diagnostic prognostic and intervention information. In: Rosenbaum P, Ronen GM, Racine E, et al. editors Ethic in child health: principles and cases in neurodisability. London MacKeith Press 2016

48. Baird G, McConachie H, Scrutton D. Parents' perceptions of disclosure of the diagnosis of cerebral palsy. Arch Dis Child. 2000; 83(6): 475-80.

49. Benzies KM, Magill-Evans JE, Hayden KA, et al. Key components of early intervention programs for preterm infants and their parents. A systematic reviews and meta-analysis. BMC Pregnancy Childbirth 2013; 13 (supl 1): 10 .

50. Aylward GP. Neurodevelopmental outcomes of infants born prematurely. J Dev Behav Pediatr. 2014; 35(6): 394-407.

51. Joo JW, Choi JY, Rha DW, et al. Neuropsychological outcomes of preterm birth in children with no major neurodevelopmental impairments in early life. Ann Rehabil Med. 2015; 39(5): 676-85.

52. Anderson PJ, Doyle LW. Cognitive and educational deficits in children born extremely preterm. Semin Perinatol. 2008; 32(1): 51-8.

53. Di Rossa G, Cavallaro T, Alibrandi A, et al. Predictive role of milestonesrelated psychomotor profiles and long-term neurodevelopmental pitfalls in preterm infants. Early Human Develop. 2016; 101: 49-55. 